\title{
Mobile Applications for Knowledge Workers and Field Workers
}

\author{
Stefan Stieglitz, ${ }^{1}$ Christoph Lattemann, ${ }^{2}$ and Tobias Brockmann ${ }^{1}$ \\ ${ }^{1}$ University of Duisburg-Essen, Forsthausweg 2, 47057 Duisburg, Germany \\ ${ }^{2}$ Jacobs University Bremen, Campus Ring 1, 28759 Bremen, Germany \\ Correspondence should be addressed to Stefan Stieglitz; stefan.stieglitz@uni-due.de
}

Received 3 September 2013; Accepted 24 February 2014

Academic Editor: David Taniar

Copyright (C) 2015 Stefan Stieglitz et al. This is an open access article distributed under the Creative Commons Attribution License, which permits unrestricted use, distribution, and reproduction in any medium, provided the original work is properly cited.

\begin{abstract}
In recent years, the diffusion of mobile applications (mobile apps) has risen significantly. Nowadays, mobile business apps are strongly emerging in business, enhancing productivity and employees' satisfaction, whilst the usage of customized individual enterprise apps is still an exception. Standardized business apps enable basic functionalities, for example, mobile data storage and exchange (e.g., Dropbox), communication (e.g., Skype), and other routine processes, which support mobile workers. In addition, mobile apps can, for example, increase the flexibility of mobile workers by easing the access to firm's information from outside the enterprise and by enabling ubiquitous collaboration. Hence, mobile apps can generate competitive advantages and can increase work efficiency on a broad scale. But mobile workers form no coherent group. Our research reveals, based on two case studies, that they can be clustered into two groups: knowledge workers and field workers. Knowledge workers and field workers fulfill different tasks and work in different environments. Hence, they have different requirements for mobile support. In this paper we conclude that standardized mobile business apps cannot meet the different requirements of various groups of mobile workers. Task- and firm-specific (individualized) requirements determine the specification, implementation, and application of mobile apps.
\end{abstract}

\section{Introduction}

Recently, mobile devices have become powerful computers, similar to desktop PCs, and mobile apps have already emerged in the business world. Nowadays, around 1.9 billion smartphones are enabled worldwide and for 2019 Ericsson predicts a worldwide total number of 5.5 billion smartphones [1]. The growth rate of smartphones is five times the rate at which personal computers were adopted in the 1980s [2]. By now, 31\% of downloaded mobile apps are used for businesses [3]. Moreover the BITKOM Net Society found out that mobile technologies, particularly mobile applications, are massively invading enterprises [4]. Organizations are adapting mobile technologies and applications increasingly for dispersed internal communication and for collaboration among business partners and customers [5].

Several studies, as those from Accenture, Gartner, and Forrester Research, depict that the usage of mobile apps in business can lead to (1) access to real-time data and ad hoc information from everywhere, (2) reduced inefficiencies in time-management of employees, (3) reduced home-to-office or office-to-office travel times, (4) saving time due to the reduction of unproductive and redundant work, (5) faster invoicing, (6) reduced stock keeping, (7) increased employees and customer satisfaction, and (8) increased quality of data and information. In general, mobile information systems can increase project performance and decrease problem response time in industries, where a large volume of information regularly arises or tight coordination among dispersed partners is necessary [6].

All this will lead to higher efficiencies at work and may lead to competitive advantages [7], especially for businesses with loosely coupled, dispersed networks [8] or in environments where partners collaborate in semistructured and uncertain situations, as can be observed in third party logistics, and in the construction and the consultancy industry. Mobile work may revolutionize working environments, conditions, and efficiencies in various business-ecosystems, if companies implement mobile management systems [9] in the right way. Companies have to thoroughly analyze their 
various types of mobile workers, the existing communication channels used by the mobile workforce, and the communication behavior of mobile workers to be able to unfold the full potential of a mobile business model.

The major strand of research on mobile collaboration covers mainly knowledge work and concentrates on sharing (un-)structured information [10]. Mobile collaboration for operational work is not the focus of the current research. Thus, research activities investigating the nature of mobile collaboration for different types of worker, for example, mobile field workers who predominantly execute structured reoccurring tasks, are underrepresented. Even mobile workers, such as construction workers and craftsmen, may profit from mobile collaboration by coordinating and communication in realtime, by reducing inefficiencies in time-management and by saving time due to reducing unproductive and redundant work. So far, research on mobile apps describes the mobile workforce as a coherent group. There exists no research on mobile apps for different types of mobile workers and business-ecosystems and their specific requirements, features, and functionalities. To close this research gap, this paper discusses the following questions.

(1) "How can mobile knowledge work and mobile field work be characterized and distinguished?" (2) "Do mobile knowledge workers and mobile field workers need different mobile apps for their work?" If mobile knowledge workers and mobile field workers have different requirements for mobile support, the following question arises: (3) "Which are basic functionalities of mobile apps that support mobile knowledge workers on the one hand, and which are basic mobile apps functionalities that support mobile field workers on the other hand?"

The remainder of this paper is structured as follows. The next section describes the importance of mobile apps as a specific type of software in the overall (mobile) strategy of companies. Moreover, a differentiation between mobile enterprise app and mobile business apps is provided. A theoretical foundation and general understanding for communication processes in companies is presented in Section 3. In Section 4 different types of mobile workers and their characteristics are identified and discussed. In Section 5 two qualitative case studies are presented in order to identify requirements of mobile apps for different types of mobile worker. In a further step, the findings are discussed and the research questions are answered. The paper ends with a conclusion, implications for corporate mobile strategies, and an outlook for further research.

\section{Background}

Mobile technologies approached a maturity stage in the last years. Mobile Internet access is ubiquitously available at relatively low costs and smartphones are equipped with multiple communication interfaces and a broad range of technologies. Since the introduction of the iPhone in 2007 the concept of mobile apps came up and massively extended the potentials of mobile devices for end-customer, as well as for the business world.
The rapid technological development of mobile devices and the mobile infrastructure as well as the usage of mobile applications has a strong influence on the way of conducting business. The newly obtained possibilities to communicate and the ubiquitous access to information are being taken up by the end-users and directly affect the communication behavior of consumers and employees [11]. This creates new benefits for enterprises. At the same time new challenges arise.

2.1. Mobile Devices as an Own Class of Hard-and Software. Mobile devices contain specific hardware components serving requirements for a mobile collaboration and communication. All hardware parts are trimmed towards low electric power consumption and have special user, hardware, storage, and communication interfaces for a mobile ecosystem. Mobile devices use specific software and operations systems with specific user interfaces and power consumption management. Mobile hard- and software can be used in a mobile environment and serve special purposes which cannot be fulfilled by conventional PCs. Hence, mobile devices such as mobile phones, smartphones, PDAs, and smart PADs must be classified and regarded as an own class of end device.

According to a survey by Research2Guidance, more than 200,000 business apps are available in consumer app stores [12]. Their number has doubled since 2011 (Q1) and it has to be considered that there exist a quite large number of enterprise apps in nonpublic app stores, operated by software vendors (e.g., SAP Afaria or Appcelerator). Mobile business apps support a wide and heterogeneous spectrum of functionalities for a multitude of tasks. They form a new and unique category of business software. They differ from traditional desktop or web based software, in that (1) mobile apps are often costless or cheap, (2) they can easily be developed for different operations systems, (3) they may use hardware-based features of the mobile device, for example, GPS and camera, (4) they have a small set of functionalities (focusing on a certain task), and (5) they can easily be used, purchased, and installed, due to the embedded app store ecosystems [13-15]. For a further analysis, standardized mobile business app and customized mobile enterprise apps will be distinguished in the following section.

2.2. Mobile Business Apps versus Mobile Enterprise Apps. In general mobile apps in business-ecosystems can be distinguished between "mobile business apps" and "mobile enterprise apps." A mobile business app is defined as standardized, "out-of-the-box" software. Mobile business apps vary in their spectrum of functionalities [7]. Typically mobile business app solutions do not need any or only less customization. Calendar, task list manager, office, or personal information management applications are examples for business app functionalities.

In contrast to this, mobile enterprise apps fulfill certain specific corporate tasks, for example, reimbursement of travel expenses [16]. They either support existing standardized workflows and business processes (mobile business process improvement), define complete new mobile-integrated business processes (mobile business process reengineering), 
TABLE 1: Mobile enterprise versus mobile business app.

\begin{tabular}{lll}
\hline Process support & Mobile business apps & $\begin{array}{l}\text { Mobile enterprise apps } \\
\text { mobile-integrated business processes }\end{array}$ \\
\hline $\begin{array}{l}\text { Interface to } \\
\text { enterprise system }\end{array}$ & No connection to the enterprise system needed & $\begin{array}{l}\text { Mobile-integrated business processes, ad hoc workflow, } \\
\text { worklets, and information intense ad hoc workflows }\end{array}$ \\
\hline Specificity & Standardized & Only usable with an interface to enterprise systems \\
\hline $\begin{array}{l}\text { Cost } \\
\begin{array}{l}\text { Distribution } \\
\text { channels }\end{array}\end{array}$ & Free or below 10€ (mostly employees carry cost) & $\begin{array}{l}\text { Individual deployments expensive, standardized apps } \\
\text { normally not free }\end{array}$ \\
\hline $\begin{array}{l}\text { Decision to use the } \\
\text { specific app }\end{array}$ & $\begin{array}{l}\text { Individual level } \\
\text { (employee) }\end{array}$ & $\begin{array}{l}\text { Enterprise app store, distribution over IMEI number or } \\
\text { public app stores }\end{array}$ \\
\hline
\end{tabular}

or focus on ad hoc workflows $[17,18]$ or on self-contained subprocesses (worklets) [18, 19]. Enterprise apps are often developed for specific firms and tasks, by the firm itself or by external vendors. To support the work processed by the employees, enterprise apps often have access to enterprise systems, for example, CRM, SCM, or ERP-systems. Yuan and Zheng [20] proclaim four basic but unique features of mobile enterprise apps: (1) mobile notifications, (2) location tracking, (3) navigation system, and (4) the possibility of a mobile, real-time assignment of tasks. These unique features can be "ideally" used in a business context for mobile communication, cooperation, and business processes [7]. Table 1 shows differences between business and enterprise apps.

2.3. Mobile Enterprise Strategies. The impact of new ways of mobile information sharing, of communication and of collaboration, needs to be understood by the management and employees and must be incorporated in the corporate culture and strategy [7].

New mobile business processes may extend the range and the effectiveness of communication and collaboration within and among firms. Employees' satisfaction and productivity outside the office can be increased by an adequate offer, support, and usage of mobile technology at work [21, 22].

This brief discussion on the effectiveness of the usage of mobile tools for different task shows that a thorough understanding of the support and usage of mobile technology on the management level as well as on the workers level is important. Hence, the whole corporate strategy, including IT infrastructure (applications, security, and management), work-life-integration, and communication cultures, is affected [7].

\section{Mobile Work}

In order to understand various needs of mobile workers for mobile apps, different types of mobile workers have to be defined and their working areas need to be outlined. The commonalities and the differences in the communication and collaboration processes of different types of mobile workers will be derived in the following.
3.1. Commonalities among Different Types of Mobile Workers. By definition, mobile workers spend a large share of their working time outside of their offices. Therefore, they strongly rely on the external access to enterprise systems and on being able to collaborate with colleagues and network partners. However, different tasks and work areas define different requirements for the usage of mobile apps. Hence, different types of mobile workers will be identified in the following subsection.

\subsection{Mobile Knowledge Workers versus Mobile Field Workers.} Yuan and Zheng [20] categorized various activities of mobile workers. They distinguish between the activities of "mobile knowledge workers" and "mobile field workers." Ware and Grantham [23] define the term "knowledge work" as "an activity that requires specific knowledge or skills or may generate new knowledge, thus creating an added value." Consequently, mobile knowledge workers are understood as employees travelling professionally and carry out contentrelated tasks [24]. Due to information deficits and asymmetries, mobile knowledge workers are only able to acquire information under increased costs $[7,25]$. As an example, IT consultants often have to make complex decisions based on expert knowledge and ad hoc information. The lack of appropriate access and insufficient provision of interfaces to firm's backend systems are reasons for information deficits. Therefore, mobile knowledge workers, such as IT consultants, have to face the lack of availability and low access to enterprise systems while being away from their stationary work place [26].

By asking 179 mobile workers, Yuan and Zheng [20] found out that the complexity of tasks of mobile knowledge workers is higher than those of mobile field workers. Knowledge work is determined by unstructured, complex tasks, and decision making, which requires in-depth information. However, the urgency for immediate information gathering and decision making is rather low.

In contrast to mobile knowledge workers, mobile field workers perform operational tasks outside the company (e.g., employees in the delivery service or service engineers) [10]. They focus on the coordination within the firm and with external partners to guarantee a smooth and sound workflow. Field workers are often confronted with reoccurring 
structured tasks. They need to rely on immediate information depending on a concrete situation, on which they are working just at that moment. Their work is characterized by high urgency and low-level decisions, which must be performed on a frequent basis. Location-based information retrieval may be of importance. Moreover, field workers require more ad hoc information and need a constant communication channel to their colleagues. For knowledge workers the availability of information and real-time coordination is of importance as the environmental context has a higher impact on the core activity of mobile field workers than on those of mobile knowledge workers [10].

It is quite plausible that more (sub-)groups of mobile workers, than the two identified in the past paragraphs, can be identified. Mobile workers with different characteristics and requirements are, for example, nurses and physicians in hospitals $[8,27,28]$ and fire fighters and people who are working in rescue activities [27, 28]. These workers could be described as intermediate types, located between mobile knowledge and mobile field workers. However, due to the fact that this is a first step in a new research field the further analysis will stick to the basic classification provided in Table 2, comparing the characteristics of mobile knowledge worker and mobile field workers.

\section{Theoretical Foundation: Communication Processes}

Different types of workers carry out different types of work. Thus, they may request a varying kind of mobile support. Different types of work require different communication and collaboration tools. Watson-Manheim and Bélanger [29] and Liu [5] found that the individual choice of communication instruments depends on various factors, such as experiences with certain devices, the task or the situation, and the location. Further, the specific needs for communication and information of the employee have an influence on the success of the usage of mobile systems [30]. Dennis and Valacich, and Daft and Lengel $[31,32]$ state that is not the type of task which is of importance for the choice of communication media but rather the type of the communications process (such as information transfer, collection of information, and interpretation of information).

Generally, communication processes can be differentiated in two groups which affect the media usage: the (a) conveyance information processes and the (b) convergence information processes. Theconveyance information processes comprise the transmission and diffusion of information. The speed and range of information diffusion are the main criteria. On the one hand, the broad availability of information may improve the quality of decision making but may lead, on the other hand, to information overload. Hence, information needs to be synchronized, bundled, structured, and transformed to knowledge, described as convergence information processes. The convergence information processes comprise the aggregation and task-related interpretation of information to reduce ambiguity. As a result, a common
TABLE 2: Mobile knowledge work versus mobile field work.

\begin{tabular}{lcc}
\hline & Knowledge workers & Field workers \\
\hline Composition & Unstructured & Structured \\
Occurrence & Irregular & Reoccurring \\
Complexity & High complexity & Less complexity \\
Urgency & Less urgency & High urgency \\
Place of work & On the road & On-site \\
Impact of decision & High impact & Low impact \\
& $\begin{array}{l}\text { Deep information } \\
\text { Information }\end{array}$ & Location based \\
& decisions support) & information \\
& &
\end{tabular}

understanding of thought patterns and knowledge base is achieved [32].

Different tasks of mobile knowledge workers and mobile field workers result in different requirements, preferred functions of mobile technologies, and distinct communication processes. To analyze ideal-type ecosystems for both groups, two qualitative case studies were conducted. In the following, the mobile knowledge workers' ecosystems and the mobile field workers' ecosystem will be analyzed to identify different needs and requirements for enterprise mobile apps.

\section{Empirical Analysis}

5.1. Method. This empirical study was carried out using case study methodology. A case study was applied because of two reasons. Firstly, this paper is an explorative paper primarily aiming at gathering qualitative data to understand and describe the basic mechanisms of mobile app usage in different business contexts. Secondly, we adopt a theory building approach and thereby endeavor to generate theoretical understanding of the usage of business and enterprise mobile apps $[13,33]$. Third, we conduct two case studies, as multiple case studies typically provide a stronger base for theory-building than a single case [34].

Data were collected through participative observations and semistructured interviews during the projects. The same semistructured questionnaire was used in both cases. Onehour face-to-face semistructured interviews with mobile workers (15 German IT consultants and 3 German managers and 3 German craftsmen in the field of real-estate restoration) were conducted to extract requirements for mobile solutions for the two different work contexts. Two independent coders, using open coding, coded the transcripts of the interviews.

5.2. Case Study 1: Mobile Knowledge Workers. Study 1 focuses on IT-consulting and company-specific communication processes. According to the definition of Ware and Grantham [23], IT consultants can be characterized as (mobile) knowledge workers. A project aimed at researching requirements from knowledge workers for mobile support to develop an appropriate mobile customer relationship management (CRM) system [7]. In the end, a solution that connects the Microsoft Dynamics CRM with smartphones was projected. 
The solution was jointly developed by the authors of this paper and affiliated business partners [21,35].

CRM processes are one of the most promising and relevant areas to support mobile access in business [36]. To specify a viable mobile CRM solution for the given ITconsulting context, system specifications had to be defined. For an in-depth system requirement analysis market research was conducted and existing mobile CRM solutions were analyzed. The market research and the findings from literature were used to define the guideline for the interviews with the IT consultants.

The market research was conducted by analyzing websites from existing vendors of mobile CRM applications. Overall 20 competitors were identified and their solutions were benchmarked along several criteria, such as access to information or workflow support.

Most of the analyzed existing applications only allow "information pull" out of the CRM system, while a minority of them allow uploading data to the CRM system. None of the evaluated applications was able to support enterprise specific processes [37, 38].

From the semistructured interviews with 15 IT consultants the following conclusion can be drawn. (1) for IT consultants (mobile knowledge workers) it is of utmost importance to have quick and easy mobile access to public information from the Internet in real-time as well as access to aggregated internal project-driven information from outside the firm. (2) Information sharing with colleagues is also important. (3) Mobile applications for mobile knowledge workers should provide general features for mobile applications as well as specific project-related features. (4) Four general functionalities are suggested to support mobile knowledge worker: (a) time tracking, (b) customer information, (c) notes, and (d) social networks.

A supplementary market analysis shows that standardized CRM solutions (business apps) do not match the demands reported from the mobile knowledge workers without any customization. No single existing solution could be identified which covers all described requirements.

5.3. Case Study 2: Mobile Field Workers. Private and public sector organizations increasingly face complex problems in environments, where dispersed, loosely coupled network partners, semistructured, or even ad hoc workflows and uncertain work scenarios characterize collaboration and business processes [39]. Domains such as case management, on-demand production, and construction projects challenge traditional, static business processes and IT systems.

Case study 2 describes an innovative new mobile collaboration solution for semistructured workflows and uncertain work scenarios for mobile field workers (real-estate restoration).

A market research showed that there is currently no suitable and already existing solution available for the given class of business-ecosystems. Six one-hour personal semistructured interviews with end-users of the applications were conducted (three contractors, one from a company with over 5.000 employees, one from a company with 200 employees that focuses on large reconstructions, and one from a company with fewer than 50 employees that focuses on bath reconstructions and a painter, an electrician, and a plumber).

Based on the interviews and based on the findings from literature, the following features were identified. Craftsmen (mobile field workers) on site need to be able to (1) document their work progress and moreover (2) administration processes should be triggered automatically, and (3) value added services such as invoicing, triggered by the documentation, released by the general contractor and wired to the financial service provider should be enabled. The possibility to have an on-site documentation increases the quality of the work by implementing a quality gate approach, where not only the general contractor but also the successive subcontractors/craftsmen check and accept the quality of the work. The new mobile collaboration infrastructure should allow dispersed and independent network partners to (4) share location-based data, messages, documents, and pictures via GPS enabled smartphones/tablets. It thereby represents a multiagent system, where interacting agents solve problems communicating and coordinating themselves via a mobile social media platform.

These kinds of services might be pivotal motives for subcontractors to join such a network. Subcontractors can easily document the work scope and quality; invoicing and other administrative services are generated automatically and on time.

Currently, a project prototype is under development. The prototype will be used to evaluate the acceptance and necessity of further functions in the context of semistructured workflows and in uncertain work scenarios, in particular in large, complex, and intertwined real-estate restoration projects $[40,41]$.

\section{Discussion}

This paper addressed three research questions. The first research question is "how can mobile knowledge work and mobile field work be characterized and distinguished?" According to the current literature two (ideal) groups of mobile workers can be identified in the given research context: "mobile knowledge workers" and "mobile field workers." Both groups of mobile workers can be described by a distinctive and unique set of characteristics. Mobile knowledge workers are generally confronted with unstructured, complex, contextual, unique, and less urgent tasks. Mobile field workers deal with simple-structured, reoccurring, urgent, hands-on, and coordinating tasks. Subgroups, who are positioned in between the two described groups of mobile workers, might be described as "mobile field workers in a knowledge intensive business-ecosystem."

Based on the case studies, the second research question, "do mobile knowledge workers and mobile field workers need different mobile apps?" could be answered positively. This leads to the third question "which are basic mobile apps functionalities supporting mobile knowledge workers on the one hand and which are basic mobile apps functionalities supporting mobile field workers on the other hand?" 
One major difference in the requirements expressed by mobile field and mobile knowledge workers for mobile apps is that a permanent access to internal corporate information is not necessarily needed for field workers, whereas this is a crucial feature for knowledge workers. Both groups need to be enabled to work during travel time. However, the characteristics of the work during travel differ fundamentally.

Results from the interviews show that mobile field workers often work in areas with low network coverage, whereas knowledge workers work in workplaces which are wellcovered by wireless networks (offices, trains, etc.).

Mobile knowledge worker is more dependent on convergence information processes; mobile field workers are sustained on conveyance information processing. The information flow among mobile field workers focuses more on coordination instead of collaboration. In contrast, knowledge workers have a need for detailed aggregated information which helps them to make decisions and perform contextual tasks. This does not mean that mobile knowledge workers have generally no need for conveyance information processing and mobile field workers have no interest in convergence information processing. It is not about an either or it is about the more and less. For example, the access to expert knowledge and the ability to share information with colleagues via mobile applications is equally important for both groups.

The relevance of functionalities differs in both groups from task to task and from environment to environment. For instance, mobile knowledge workers may profit from direct access to enterprise systems and ubiquitous access to information and resources while working on conceptual tasks. When focusing on building ad hoc networks or personal task management, this might not be a required function. In contrast, the need for collaboration tools exists in most working scenarios for mobile field workers.

Additionally, organizations will also face different challenges (e.g., information overload, convincing employees to use the mobile applications, security concerns) when adapting mobile applications into work routines. The adoption of mobile apps mainly depends on successful change management, but nevertheless it is crucial to develop targetoriented apps.

\section{Conclusion}

The spectrum of services provided by standardized mobile business apps is usually limited. Existing mobile apps and research on mobile collaboration focus mainly on knowledge work and consequently on mobile knowledge workers. But mobile collaboration is not limited to knowledge intensive industries with uncertain working environments.

This study shows that different groups of mobile workers require different types of mobile technology for their daily work. Two ideal groups of mobile workers with unique requirements for mobile support were identified in this paper, the mobile knowledge worker and the mobile field worker. Both groups work in completely different businessecosystems.
Standardized mobile business apps often do not offer innovative solutions for loosely coupled work, where workers collaborate on demand and during irregular, unpredictable periods of time. Interfaces and functionalities cannot meet the specific requirements for this flexible way of information sharing or collaboration of different types of mobile workers. Therefore, unique, customized enterprise applications adapted to specific mobile business processes and different types of mobile work are needed. This applies for both types of mobile workers. It, therefore, makes sense for corporations to analyze working environments, to evaluate the underlying communication processes and the needs for mobile support before designing or selecting mobile applications.

Furthermore, the whole corporate strategy may be affected if a corporation transforms from a traditional business concept to a mobile concept. This affects not only IT infrastructure (hardware, software, interfaces, security, and management) but also social aspects such as work-lifeintegration and the communication and cooperation culture [11].

However, the presented research has some limitations. This conceptual work is grounded on merely two qualitative case studies and a quite small number of interviews. Generalizations should be avoided and interpretations and comparisons to other domains should be drawn with great caution as well. Further research might concentrate on the evaluation of applied mobile applications, throughout logfile-analysis or surveys among the employees. Moreover, the findings are the basis to build up a framework for further research on mobile business and mobile enterprise apps. This framework is defined by three dimensions: (1) different types of mobile apps (business apps or mobile app), (2) different groups of mobile workers, and (3) different types of tasks (information and knowledge processes). Along these lines further research can be conducted in a structured way.

\section{Conflict of Interests}

The authors declare that there is no conflict of interests regarding the publication of this paper.

\section{References}

[1] R. Qureshi, Ericsson Mobility Report-On the Pulse of the Networked Society, Ericsson, 2014.

[2] M. DeGusta, "Are smart phones spreading faster than any technology in human history?" MIT Technology ReportBusiness Report, MIT, 2014, http://www.technologyreview .com/news/427787/are-smart-phones-spreading-faster-than-anytechnology-in-human-history/.

[3] N. Mohr, A. K. Sauthoff-Bloch, M. Alt, and J. Derksen, StudyMobile Web Watch, Accenture, 2009.

[4] Bitkom, "Smartphones stärker verbreitet als normale Handys," Bundesverband Informationswirtschaft, Telekommunikation und neue Medien e.V., 2014.

[5] C. Liu, "Measuring and prioritising value of mobile phone usage," International Journal of Mobile Communications, vol. 8, no. $1,2010$. 
[6] N. Šuman and M. Pšunder, "Mobile computing changing the traditional ways of organizing the construction company," American Journal of Applied Sciences, vol. 5, no. 1, pp. 42-47, 2008.

[7] S. Stieglitz and T. Brockmann, "Increasing organizational performance by transforming into a mobile enterprise," MIS Quarterly Executive, vol. 11, no. 4, 2012.

[8] D. Pinelle and C. Gutwin, "Loose coupling and healthcare organizations: deployment strategies for groupware," Computer Supported Cooperative Work, vol. 15, no. 5-6, pp. 537-572, 2006.

[9] K. Ortbach, T. Brockmann, and S. Stieglitz, "Drivers for the adoption of mobile device management in organizations," in Proceedings of the 22nd European Conference on Information Systems (ECIS '14), Tel Aviv, Israel, 2014.

[10] Y. Yuan, N. Archer, C. E. Connelly, and W. Zheng, "Identifying the ideal fit between mobile work and mobile work support," Information \& Management, vol. 47, no. 3, pp. 125-137, 2010.

[11] A. Stubblefield, M. Carter, S. Jones, and C. Siffre, "The role of social capital in cell phone adoption behavior," in Proceedings of the Diffusion Interest Group in Information Technology Workshop (DIGIT '10), Paper 4, St. Louis, Mo, USA, 2010.

[12] Research2Guidance, The Enterprise Mobile App Market Status Report, 2012.

[13] H. Heitkötter, K. F. Hildebrand, and C. A. Usener, "Mobile platforms as two-sided markets," in Proceedings of the 18th Americas Conference on Information Systems (AMCIS '12), Paper 11, pp. 2644-2652, August 2012.

[14] I. Kouris and R. Kleer, "Business models in two-sided markets: an assessment of strategies for App platforms," in Proceedings of the International Conference on Mobile Business (ICMP '12), Paper 22, 2012.

[15] B. Bergvall-Kareborn and D. Howcroft, "Mobile applications development on apple and google platforms," Communications of the Association for Information Systems, vol. 29, article 30, 2011.

[16] B. Hess, J. J. Sutanto, M. Ameling, and F. von Reischach, "A business-to-business perspective on mobile application," in Proceedings of the International Conference on Mobile Business, p. 25, 2012.

[17] S. Dustdar, "Caramba-a process-aware collaboration system supporting ad hoc and collaborative processes in virtual teams," Distributed and Parallel Databases, vol. 15, no. 1, pp. 45-66, 2004.

[18] L. Goeke and K. Pousttchi, "Influencing factors for the introduction of mobile-integrated business processes," in Proceedings of the 9th International Conference on Electronic Business (ICEB '09), pp. 733-738, December 2009.

[19] M. Adams, A. ter Hofstede, D. Edmond, and W. van der Aalst, "Worklets: a service-oriented implementation of dynamic flexibility in workflows," in On the Move to Meaningful Internet Systems 2006: CoopIS, DOA, GADA, and ODBASE, vol. 4275 of Lecture Notes in Computer Science, pp. 291-308, 2006.

[20] Y. Yuan and W. Zheng, "Mobile task characteristics and the needs for mobile work support: a comparison between mobile knowledge workers and field workers," in Proceedings of the 8th International Conference on Mobile Business, pp. 7-11, IEEE, Dalian, China, June 2009.

[21] T. Brockmann and S. Stieglitz, "Specification of mCRM enterprise applications to support IT-consultants," in Proceedings of the 27th IEEE International Conference on Advanced Information Networking and Applications (AINA '13), pp. 1495-1500, Barcelona, Spain, March 2013.
[22] V. Mladenova, M. Homann, H. Kienegger, H. Wittges, and H. Krcmar, "Towards an approach to identify and assess the mobile eligibility of business processes," in Proceedings of the 17th Americas Conference on Information Systems (AMCIS '11), pp. 2360-2370, Detroit, Mich, USA, August 2011.

[23] J. P. Ware and C. E. Grantham, Knowledge Work and Knowledge Workers, The Work Design Collaborative, LLC for WIRED West Michigan, 2007.

[24] M. Perry, K. O'Hara, A. Sellen, B. Brown, and R. Harper, "Dealing with mobility: understanding access anytime, anywhere," ACM Transactions on Computer-Human Interaction, vol. 8, no. 4, pp. 323-347, 2001.

[25] D. Garlan, V. Poladian, B. Schmerl, and J. P. Sousa, "Taskbased self-adaptation," in Proceedings of the 1st ACM SIGSOFT Workshop on Self-Managing Systems (WOSS '04), pp. 54-57, November 2004

[26] S. Albolino, M. Distratis, T. Schael, and G. Sciarra, "Mobile knowledge worker," in Proceedings of the 5th International Conference on Organizational Learning and Knowledge, Lancaster, UK, 2003.

[27] Á. Monares, S. F. Ochoa, J. A. Pino, V. Herskovic, J. RodriguezCovili, and A. Neyem, "Mobile computing in urban emergency situations: improving the support to firefighters in the field," Expert Systems with Applications, vol. 38, no. 2, pp. 1255-1267, 2011.

[28] E. B. Morán, M. Tentori, V. M. González, J. Favela, and A. I. Martinez-Garcia, "Mobility in hospital work: towards a pervasive computing hospital environment," International Journal of Electronic Healthcare, vol. 3, no. 1, pp. 72-89, 2007.

[29] M. B. Watson-Manheim and F. Bélanger, "Communication media repertoires: dealing with the multiplicity of media choices," MIS Quarterly, vol. 31, no. 2, pp. 267-293, 2007.

[30] K. Riemer and S. Filius, "Contextualizing media choice using genre analysis," Business \& Information Systems Engineering, vol. 51, no. 2, pp. 192-205, 2008.

[31] R. L. Daft and R. H. Lengel, "Organizational information requirements, media richness and structural design," Management Science, vol. 32, no. 5, pp. 554-571, 1986.

[32] A. R. Dennis and J. S. Valacich, "Rethinking media richness: towards a theory of media synchronicity," in Proceedings of the 32nd Annual Hawaii International Conference on System Sciences (HICSS '99), p. 12, Maui, Hawaii, USA, January 1999.

[33] K. M. Eisenhardt, "Building theories from case-study research," Academy of Management Review, vol. 14, no. 4, pp. 532-550, 1989.

[34] R. K. Yin, Case Study Research: Design and Methods, Sage, Beverly Hills, Calif, USA, 1984.

[35] T. Brockmann, S. Stieglitz, J. Kmieciak, and S. Diederich, "User acceptance of mobile business intelligence services," in Proceedings of the 1st International Workshop on Web Services and Social Media (WSSM '12), pp. 862-866, Melbourne, Australia, 2012.

[36] C. Lattemann and S. Robra-Bissantz, "Customer governanceIC based concepts for a successful customer integration," in Frontiers of e-Business Research, pp. 193-206, 2006.

[37] BFI Mobile, Mobile Client für Microsoft Dynamics CRM, 2012, http://www.bfi-mobile.com/de/.

[38] S. S. C. Shang and Y. F. Ko, "Understanding the technology and organizational elements of customer relationship management systems," in Proceedings of the 12th Americas Conference on Information Systems (AMCIS '06), pp. 2549-2557, August 2006. 
[39] P. Antunes, V. Herskovic, S. F. Ochoa, and J. A. Pino, "Structuring dimensions for collaborative systems evaluation," ACM Computing Surveys, vol. 44, no. 2, article 8, pp. 8-36, 2012.

[40] J. L. A. Herrera, Contribution to Quality-driven Evolutionary Software Development Process for Service-Oriented Architecture, 2006.

[41] V. Kumar, G. Ramani, and T. Bohling, "Customer lifetime value approaches and best practice applications," Journal of Interactive Marketing, vol. 18, no. 3, pp. 60-72, 2004. 

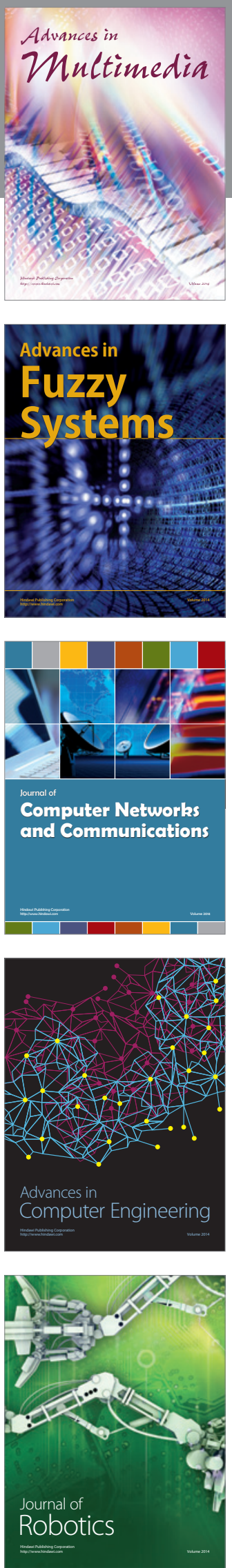

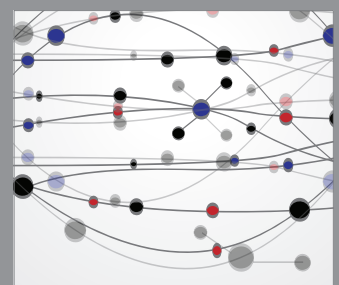

The Scientific World Journal
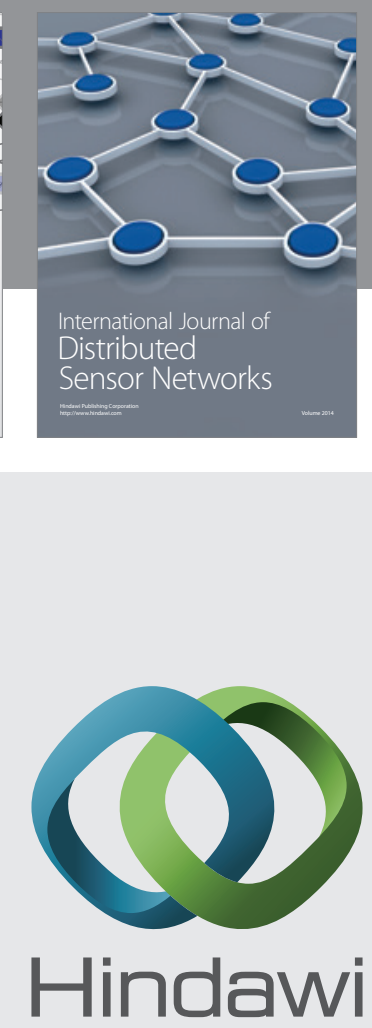

Submit your manuscripts at

http://www.hindawi.com
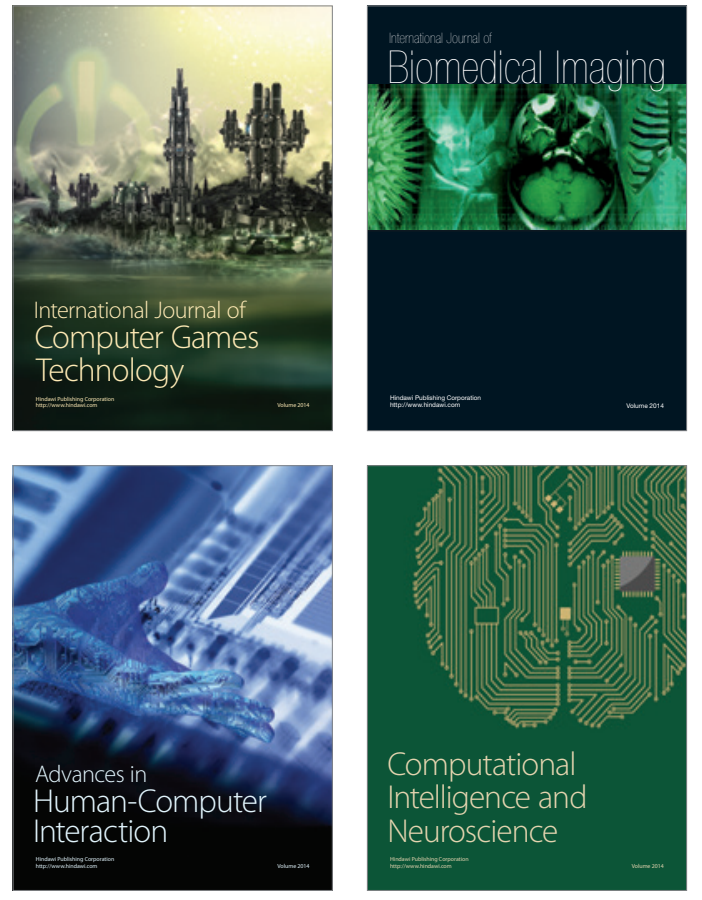
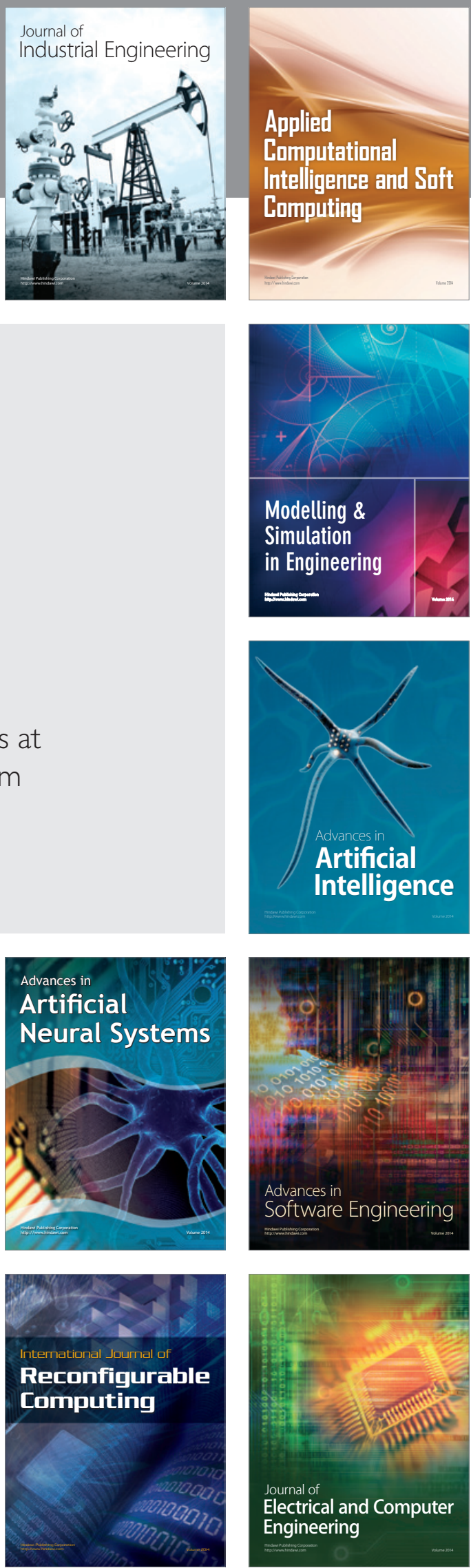